\title{
Platynosomum fastosum (Trematoda: Dicrocoeliidae) from Cats in Vietnam: Morphological Redescription and Molecular Phylogenetics
}

\author{
Hung Manh Nguyen ${ }^{1, *}$, Hien Van Hoang', Loan Thi Ho \\ ${ }^{1}$ Department of Parasitology, ${ }^{2}$ Department of Molecular Systematics and Conservation Genetics, Institute of Ecology and Biological Resources \\ (IEBR), Vietnam Academy of Science and Technology (VAST), Hanoi, Vietnam
}

\begin{abstract}
The present study was performed to reveal the morphological characteristics and molecular phylogenetic position of Platynosomum fastosum Kossack, 1910. A total 167 specimens of $P$. fastosum were collected in $8(4.9 \%)$ out of 163 sets of gall-bladders and bile ducts of cats. The number of worms was 1-105 per infected cat. This species was characterized by having a long and slender body, slightly larger ventral sucker than the oral sucker, indistinct prepharynx, small pharynx, short esophagus, bifurcation midway between 2 suckers, and ceca extending to the posterior end of the body. The length of the partial sequences of ITS1 and $5.8 \mathrm{~S}$ rDNA of $P$. fastosum were $990 \mathrm{bp}, \mathrm{GC}$-rich. AT/GC ratio was 0.9 , there were 9 polymorphic sites, and intraspecific variations ranged from $0.1 \%$ to $0.9 \%$. Phylogenetic analyses by neighbor-joining phylogram inferred from ITS1 rDNA sequences revealed that the genetic distance between $P$. fastosum specimens ranged from 0.3 to $1.5 \%$ while the smallest interspecific distance among dicrocoeliid species was $20.9 \%$. The redescription and genetic characters of $P$. fastosum are taxonomically important to recognize future different species of the genus Platynosomum showing high intraspecific and morphological variability.
\end{abstract}

Key words: Platynosomum fastosum, nuclear ribosomal DNA, morphometry, phylogenetics, dicrocoeliid, hepatic trematode

\section{INTRODUCTION}

The hepatic trematode, Platynosomum fastosum Kossack, 1910 is one of the most important and widely distributed (geographically) parasites of cats [1]. In Asian countries, this species has been found from domestic cats in Indonesia [2], Korea [3], Malaysia [4,5], Thailand [6,7], and Southern Vietnam [8]. P. fastosum has also been found in wild animals, including the small Asian mongoose, Herpestes javanicus (Saint-Hilaire), in Central Highlands of Vietnam [9]. Additionally, P. fastosum is known to cause pathological symptoms, including cholangiocarcinomas in the liver [10].

P. fastosum was treated to be synonymous with other dicrocoeliid species because of intraspecific morphological variations [11]. Maldonado [12] treated 3 Platynosomum species, i.e., P. fastosum, P. concinnum (Braun, 1901), and P. illiciens (Braun, 1901), recovered in the gallbladder and bile ducts of cats, as

- Received 23 August 2016, revised 8 December 2016, accepted 5 January 2017.

*Corresponding author (hung_iebr@yahoo.com)

(c) 2017, Korean Society for Parasitology and Tropical Medicine

This is an Open Access article distributed under the terms of the Creative Commons Attribution Non-Commercial License (http://creativecommons.org/licenses/by-nc/4.0) which permits unrestricted non-commercial use, distribution, and reproduction in any

medium, provided the original work is properly cited. the same species. Nguyen and Ha [13] reckoned that Eurytrema rebelle Railliet, 1924 is one of the synonyms of $P$. fastosum. Some other dicrocoeliid flukes, such as P. planicipitus, Dicrocoelium concinnum, D. lanceolatum var. symmetricum, and Concinnum concinnum, were also considered to be the same species as P. fastosum [1]. Recently, Pinto et al. [11] mentioned that no significant morphological differences were observed between $P$. fastosum and P. illiciens even though they parasitize different host species; mammals and birds, respectively. There are, however, no molecular studies on Platynosomum spp. up to the present to confirm the opinions of the above authors.

Among all target sequences used for phylogenetic and diagnostic studies, ribosomal DNA (rDNA) is a useful genetic marker for examining taxonomic status of digeneans [14]. Especially, the internal transcribed spacer (ITS1) regions of rDNA may provide useful information for elucidating interspecific and intraspecific relationships among closely related genera in many eukaryotes [15-17].

In the present study, we redescribed to give the species validity of $P$. fastosum with reinforced morphometric data and provided the phylogenetic data and partial sequences of the ITS1-5.8S rDNA, for more precise characterization of this fluke species. Phylogenetic relationships among the different species of hepat- 
ic trematodes (including dicrocoeliid species) were also inferred from the ITS1 rDNA sequences to elucidate their positions.

\section{MATERIALS AND METHODS}

\section{Surveyed area and worm recovery}

A survey for the recovery of liver flukes was performed with gall-bladder and bile ducts of cats obtained in slaughter houses located in Thai Binh province in Northern Vietnam from April 2012 to July 2015. The gall-bladder and bile ducts of each cat were removed and stored separately in plastic bags, placed on ice, and carried fresh from the slaughter houses to the laboratory. In the laboratory, the samples were necropsied following the method described by Skrjabin [18]. The gallbladder and bile ducts of the cats were opened by scissors, carefully not to cut too deeply and keep the tip of the scissors pointed upwards and do not damage the underlying structures. After that, these organs were rinsed in the sink and then checked for the presence of liver trematodes under a stereomicroscope Olympus SZ61.

\section{Morphological observations}

Trematodes were removed from debris, counted, and identified primarily using the keys by Bray et al. [19] and Nguyen [20]. Some P. fastosum, which were chosen for morphological studies, were transferred to a drop of saline on a microscope slide and covered with a coverslip. The slide and the coverslip were gently rolled by a thread to prevent it from moving. They were fixed in warm AFA (a mixture of 70\% ethanol-formalinacetic acid in the ratio of 90:7:3), preserved in 70\% ethanol, stained with Mayer's carmine, dehydrated using a graded ethanol series (80-100\%), cleared in xylene, and mounted in Canada balsam [21]. The morphology of $P$. fastosum was studied using a light microscope Olympus $\mathrm{CH} 40$ at magnifications of $\times 40$ to $\times 400$. Drawings were made with the aid of a camera lucida, and were redrawn using Adobe Illustrator CS6. All measurements are given in micrometers with the range followed by the mean in parentheses. Other $P$. fastosum specimens were preserved in absolute ethanol for molecular studies.

\section{DNA extraction, PCR, and sequencing}

DNA from 3 specimens of $P$. fastosum, collected from 3 individually infected cats, was extracted using the DNeasy Blood and tissue kit (Qiagen, Hilden, Germany). Partial fragments of ITS1-5.8S rDNA were amplified by PCR using the following primer pair; 5,8SR: 5'-CAT GGC CGC AAT ATG CTT GCA-3' and 18SF: 5'-CCT GGT AAG TGC AAG TCA GAT GC-3'. PCR was performed in a total volume of $20 \mu \mathrm{l}$ and contained 0.25 $\mathrm{mM}$ of each primer, $1 \mu \mathrm{l}$ of DNA, 2x Taq PCR Mastermix (Promega, Madison, Wisconsin, USA). Amplification of the partial sequence of ITS1-5.8S was performed on a Eppendorf Mastercycle using the following cycling conditions: 2 min initial denaturation step at $95^{\circ} \mathrm{C}, 35$ cycles of $30 \mathrm{sec}$ at $95^{\circ} \mathrm{C}, 30 \mathrm{sec}$ at $53^{\circ} \mathrm{C}$ and $1 \mathrm{~min}$ at $72^{\circ} \mathrm{C}$, and a 7 -min extension at $72^{\circ} \mathrm{C}$. The PCR products of the partial sequences for $3 P$. fastosum specimens were sent to First Base Company for sequencing using BD1primer 5'-TCGTAACAAGGTTTCCGTA-3' [22]. The results of sequencing were checked by eye using Chromas software.

The 3 newly obtained ITS1-5.8S partial sequences of $P$. fastosum were deposited in GenBank database under accession nos. KU987672-KU987674. These sequences were aligned and examined for variable sites using the MEGA 6.0.6 program [23].

\section{Phylogenetic analyses}

Neighbor-joining phylogram inferred from the ITS1 rDNA sequences were constructed with the Kimura- 2 parameter model [24] using computer software program package PAUP* 4.0 beta [25]. ITS1 sequences of Fasciola gigantica (acecession no. AB553651) were used as an outgroup for constructing the tree. Additionally, ITS1 sequences of opisthorchiid and dicrocoeliid species were used as references (Table 1). Bootstrap analyses were conducted using 1,000 replicates for a phylogenetic tree. Estimates of evolutionary divergence between the ITS1 rDNA sequences were calculated by MEGA 6.0.6 [23] in consideration with all substitutions and missing and/or gaps

Table 1. Classification and accession numbers of species included in the phylogenetic analysis

\begin{tabular}{llll}
\hline Family & \multicolumn{1}{c}{ Genus } & \multicolumn{1}{c}{ Species } & Accession no. \\
\hline Opisthorchiidae & Metorchis & M. bilis & EU038154 \\
& & M. xanthosomus & JQ716400 \\
& M. orientalis & HM347225 \\
& Opisthorchis & O. felineus & KT020833, \\
& & EU038140 \\
& O. viverrini & EU038141 \\
& & C. sinensis & KF734795, \\
Dicrocoeliidae & Dicrocoelium & D. dendriticum & KF734791 \\
& & & KC774522, \\
& & D. chinensis & KF7347516 \\
& & KF734791 \\
Fasciolidae & Fasciola & F. gigantica & AB553651 \\
\hline
\end{tabular}


as unambiguous changes, and analyses were used the maximum composite likelihood model.

\section{RESULTS}

\section{Worm recovery}

A total of 163 sets of gall-bladders and bile ducts of cats were examined. P. fastosum was found in 8 cats (4.91\%) with 167 specimens, and ranged from 1 to 105 specimens, with a mean of 21 per infected cat. Multiparasitism of hepatic trematodes in cats at study sites was not common, only 2 cats were found infected with 2 species, P. fastosum and Opisthorchis viverrini (Poirier, 1886).

\section{Taxonomic position and morphological descriptions}

Family Dicrocoeliidae Odhner, 1911

Genus Platynosomum Looss, 1907

Platynosomum fastosum Kossack, 1910 (Fig. 1)

Host: Felis catus

Habitat in host: gallbladder and bile duct of liver

Locality: Dong Hung and Quynh Phu districts (Thai Binh province, Vietnam)

Deposition of specimens: 14 specimens (NMH-Platynosomum-2015-1-14) are deposited in the Department of Parasitology, Institute of Ecology and Biological Resources. Two other specimens are deposited in the Vietnam National Museum of Nature, Vietnam.

Redescription (Based on 16 specimens; measurements in Table 2): Body slender, elongate, with greatest width at midlength and tapering at both anterior and posterior end; length/ width ratio 5.16. Oral sucker muscular, subterminal, more or less spherical. Ventral sucker about $1 / 4$ of the body length from anterior end, transversely oval, protuberant, slightly larger than oral sucker; sucker width ratio 1.09. Prepharynx very short, indistinct, entirely dorsal to oral sucker. Pharynx small, subglobular; oral sucker/pharynx width ratio 2.94. Esophagus short, bifurcates midway between 2 suckers. Intestinal caeca 2 , extending towards the posterior end of body, terminate at mid-region of posterior quarter of body.

Testes 2, large, symmetrical, oblong oval, slightly lobed, longer than wide, postero-lateral and positioned on either side of ventral sucker, and separated by coils of uterus. Functional cir-

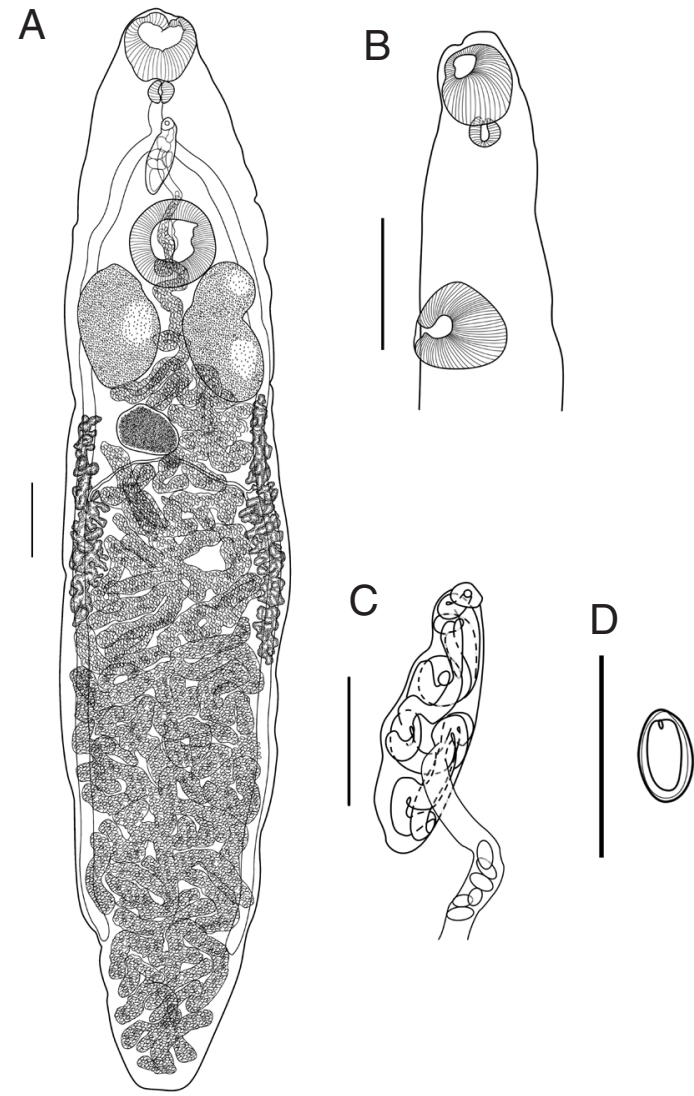

Fig. 1. (A) Platynosomum fastosum whole-mount, ventral view. Scale bar $=400 \mu \mathrm{m}$. (B) Optical sagittal section of the anterior end of body. Scale bar $=400 \mu \mathrm{m}$. (C) Genital complex. Scale bar $=200$ um. (D) Egg. Scale bar $=100 \mu \mathrm{m}$.

rus-sac relatively small, with thin muscular wall, enclosing convoluted seminal vesicle, pars prostatica and short ejaculatory duct, anterior border of ventral sucker. Common genital pore antero-sinistral to intestinal bifurcation.

Ovary entire, sometimes lobed, transversely elongate, smaller than testes, submedian, posterior to 1 of the testes. Seminal receptacle nearly spherical, smaller than ovary, postero-dorsal and positional between 2 testes. The duct of seminal receptacle passes posteriorly and joined by oviduct and then by Laurer's canal, passes transversely to ovary then joined by duct from vitelline reservoir, then enters Mehlis' gland beside ovary. Vitellarium follicular; follicles in 2 lateral fields extending from vicinity of posterior margin of testes, surrounding ceca, terminate in mid-region of the $3 / 4$ of body; right band of vitellarium normally shorter than left. Vitelline reservoir immediately posterior to ovary. Uterine coils fill entire hindbody, contain numerous clear to golden brown eggs; anteriorly uterus shows minor coiling in forebody, passes dorsal to ventral sucker, and 
Table 2. Morphometrics of Platynosomum fastosum in domestic cats collected in slaughter houses in Northern Vietnam, compared with those reported by previous authors

\begin{tabular}{|c|c|c|c|c|c|c|}
\hline Host species & Felis catus & Rupornis magnirostris & Herpestes javanicus & Canis familaris & Mus musculus & F. catus \\
\hline Reference & \multicolumn{2}{|c|}{ Travassos [26] } & $\mathrm{Ha}[9]$ & $\overline{\text { Nguyen et al. [31] }}$ & Pinto et al. [11] ${ }^{\mathrm{b}}$ & Present study \\
\hline Locality & \multicolumn{2}{|r|}{ Brazil } & \multicolumn{2}{|c|}{ Vietnam } & Brazil & Vietnam \\
\hline Body length & $3,000-6,000$ & $2,900-6,700$ & $2,006-3,480(3,160)$ & 5,580 & $2,235-4,986(3,723)$ & $2,870-6,335(5,290)$ \\
\hline Maximum body width & $1,600-2,400$ & $900-1,700$ & $600-1,160$ & 1,910 & $860-1,719(1,362)$ & $697-1,435(1,026)$ \\
\hline Oral sucker & $\begin{array}{c}360-480 \\
\times 360-480\end{array}$ & $\begin{array}{l}420-630 \\
\times 420-630\end{array}$ & $\begin{array}{c}129-374 \\
\times 129-387\end{array}$ & $520 \times 450$ & $\begin{array}{l}239-423(336) \\
\times 246-348(300)\end{array}$ & $\begin{array}{c}246-430(357) \\
\times 235-472(362)\end{array}$ \\
\hline Pharynx & $\begin{array}{c}120-150 \\
\times 120-150\end{array}$ & $\begin{array}{c}150-180 \\
\times 150-180\end{array}$ & $\begin{array}{l}45-113 \\
\times 48-103\end{array}$ & $150 \times 130$ & $\begin{array}{l}82-150(124) \\
\times 68-137(107)\end{array}$ & $\begin{array}{c}82-156(124) \\
\times 90-148(123)\end{array}$ \\
\hline Oesophagus length & - & - & - & 130 & - & 139-187 (182) \\
\hline Ventral sucker & $\begin{array}{l}420-540 \\
\times 420-540\end{array}$ & $\begin{array}{c}390-720 \\
\times 390-720\end{array}$ & $\begin{array}{c}194-413 \\
\times 219-452\end{array}$ & 550 & $\begin{array}{c}253-430(327) \\
\times 239-396(326)\end{array}$ & $\begin{array}{c}295-525(445) \\
\times 270-500(396)\end{array}$ \\
\hline Right testis & $\begin{array}{c}200-960 \\
\times 180-720\end{array}$ & $\begin{array}{c}300-500 \\
\times 250-780\end{array}$ & $\begin{array}{l}168-531(430) \\
\times 194-452(290)\end{array}$ & $698 \times 628$ & $\begin{array}{c}355-887(599) \\
\times 232-546(395)\end{array}$ & $\begin{array}{l}238-697(431) \\
\times 98-360(258)\end{array}$ \\
\hline Left testis & $\begin{array}{c}200-960 \\
\times 180-720\end{array}$ & $\begin{array}{c}300-500 \\
\times 250-780\end{array}$ & $\begin{array}{l}232-516(420) \\
\times 319-413(320)\end{array}$ & $698 \times 628$ & $\begin{array}{c}341-881(619) \\
\times 239-580(400)\end{array}$ & $\begin{array}{c}246-779(459) \\
\times 106-377(259)\end{array}$ \\
\hline Ovary & $\begin{array}{l}90-540 \\
\times 60-420\end{array}$ & $\begin{array}{l}310-420 \\
\times 420-529\end{array}$ & $\begin{array}{l}103-260(200) \\
\times 129-258(260)\end{array}$ & $279 \times 279$ & $\begin{array}{c}102-294(197) \\
\times 171-389(294)\end{array}$ & $\begin{array}{l}131-402(280) \\
\times 131-476(279)\end{array}$ \\
\hline $\begin{array}{l}\text { Right band of } \\
\text { vitellarium' length }\end{array}$ & - & - & 730 & 1,040 & - & $\begin{array}{c}533-1,845(1,196) \\
\times 143-328(218)\end{array}$ \\
\hline $\begin{array}{l}\text { Left band of } \\
\text { vitellarium' length }\end{array}$ & - & - & 730 & 1,220 & - & $\begin{array}{c}594-1,681(1,122) \\
\times 144-476(228)\end{array}$ \\
\hline Cirrus sac & $\begin{array}{c}420-540 \\
\times 120\end{array}$ & $\begin{array}{l}290-720 \\
\times 110-180\end{array}$ & $420 \times 80$ & $380 \times 140$ & $\begin{array}{l}280-478(363) \\
\times 102-171(129)\end{array}$ & $\begin{array}{l}320-476(406) \\
\times 98-164(129)\end{array}$ \\
\hline Egg & - & - & $24-39 \times 15-24$ & $41-47 \times 27-30$ & - & $\begin{array}{l}40-50(43) \\
\times 20-30(24)\end{array}$ \\
\hline
\end{tabular}

The specimens of $P$. fastosum was originally described as Eurytrema rebelle $e^{a}$ and $P$. illiciens ${ }^{b}$.

Table 3. The intraspecific variation in the $P$. fastosum ITS1-5.8S rDNA partial sequences

\begin{tabular}{|c|c|c|c|c|c|c|c|c|c|}
\hline \multirow{2}{*}{ Accession number } & \multicolumn{9}{|c|}{ Position of polymorphic site } \\
\hline & 424 & 426 & 428 & 596 & 646 & 807 & 918 & 937 & 957 \\
\hline KU987674ª & $G$ & $A$ & $G$ & $A$ & $A$ & $G$ & $\mathrm{~T}$ & $\mathrm{~T}$ & $\mathrm{~T}$ \\
\hline KU987672a & . & . & . & . & . & . & $G$ & . & . \\
\hline KU987673 & $A$ & $G$ & $A$ & $\mathrm{~T}$ & C & $A$ & . & $G$ & C \\
\hline
\end{tabular}

athe sequence was taken from local cat.

bthe sequence was taken from "long transportation" cat.

enters cirrus-sac before opening in the common genital pore.

\section{Sequence and phylogenetic analyses}

Partial sequences of ITS1-5.8S of $P$. fastosum were $990 \mathrm{bp}$ in length, GC-rich; AT/GC ratio was estimated to be 0.9 , and nucleotide frequencies were $20.1 \%, 24.4 \%, 27.8 \%$, and $27.3 \%$ for A, C, G, and T, respectively. A total of 9 polymorphic sites (Table 3) were detected with 5 transitions $(\mathrm{A} \leftrightarrow \mathrm{G}$ or $\mathrm{T} \rightarrow \mathrm{C}$ ) and 4 transversions $(\mathrm{A} \rightarrow \mathrm{C}, \mathrm{A} \rightarrow \mathrm{T}$, and $\mathrm{T} \rightarrow \mathrm{G}$ ). The ITS1-5.8S intraspecific variations ranged from $0.1 \%$ to $0.9 \%$ in the P. fastosum specimens studied.

The neighbor-joining phylogram inferred from ITS1 rDNA comprised 3 lineages of opisthorchiid, dicrocoeliid, and fasciolid species. In the lineage of dicrocoeliid species, all sequences of $P$. fastosum were formed a monophyletic clade; it was separated with other clades of Dicrocoelium spp. (Fig. 2). The estimation of evolutionary divergence value showed that the genetic distance between $P$. fastosum specimens ranged from 0.3 to $1.5 \%$, while the smallest interspecific distance among dicrocoeliid species was $20.9 \%$.

\section{DISCUSSION}

Because no local farm produces cat meat in Northern Viet- 


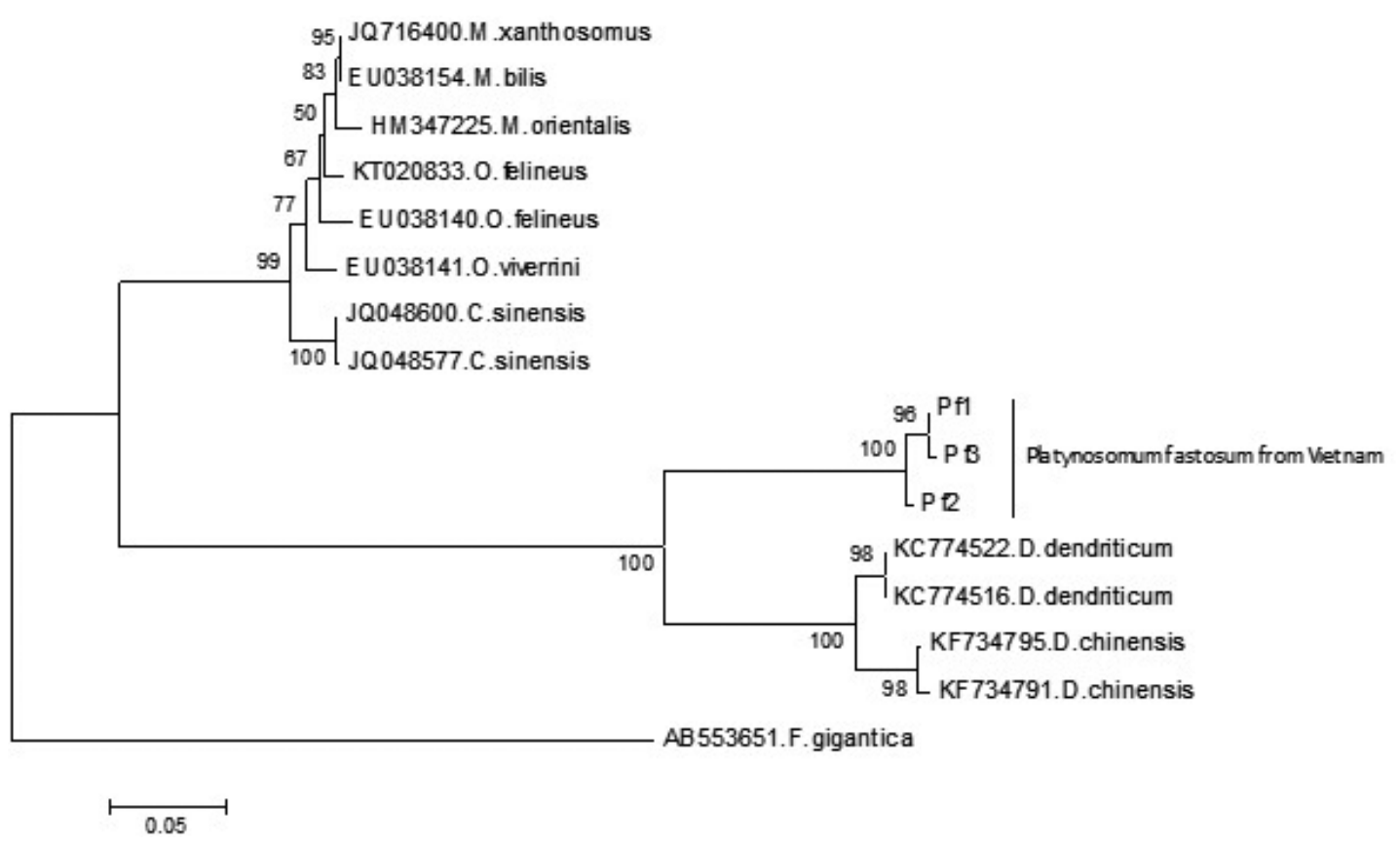

Fig. 2. A neighbor-joining phylogram inferred from ITS1 rRNA sequences of Platynosomum fastosum from Vietnam and other related reference flukes in the family Dicrocoeliidae and Opisthorchiidae. The ITS1 rRNA sequence of Fasciola gigantica was used as an outgroup. Bootstrap values higher than $50 \%$ are shown on the tree node.

nam, cats are bought from different places and transported to slaughter houses. We have been informed by the slaughter houses that cat sources are mainly from the South of Vietnam, and neighboring countries, such as China, Laos, Cambodia, and Thailand. Cats are purchased through middlemen from various areas and hence their origin is difficult to determine. However, local cats (collected from Thai Binh and several neighboring provinces, e.g., Ninh Binh, Nam Dinh, and Ha Nam) were kept separately in cages, and they were maintained longer because of stronger and little stress after short transportation to compare with other cats.

The coinfection of hepatic trematodes (O. viverrini and $P$. fastosum) was found only in "long transportation" cats; in 3 infected specimens of local cats only found was $P$. fastosum. The geographical distribution of $O$. viverrini is known in Thailand, Laos, Cambodia, and Southern Vietnam [28,29], so the presence of $O$. viverrini in Northern Vietnam can be explained by transportation of cats from these endemic areas to the slaughter houses/restaurants. The transportation of animals without epidemiological control could be a reason for spread of diseases, including opisthorchiasis from endemic areas to new areas.

Although Pinto et al. [11] and Maldonado [12] believed that $P$. fastosum is a synonym of $P$. illiciens, the shape of testes is significantly different between $P$. fastosum and P. illiciens. The tes- tes of $P$. fastosum are entire, sometimes slightly lobed, while they are deeply lobed in P. illiciens [27]. This character is sufficiently distinct to justify the distinct species status intermediate within Platynosomum spp. or other taxon. In addition, the body size and length/width ratio of $P$. fastosum in this study were greater than those in P. illiciens [11]; even other morphometrical measurements were similar between 2 species.

Nguyen et al. [30] found P. fastosum from dogs, but the authors classified it as Eurytrema rebelle. The morphological characters of $P$. fastosum and E. rebelle are similar; however, the common genital pore of Platynosomum opens at the level of or above the intestinal bifurcation, while it opens posterior to intestinal bifurcation in Eurytrema. Currently, the identification of dicrocoeliid species have been traditionally based on the morphological characteristics of the adult worms, but these criteria of the differentiation are often insufficient for determination; therefore, the molecular genetic approach could be used to identify closely related species.

Up to the present, the applied DNA technology for studying dicrocoeliid species is limited. Only few species have had genetic data, mainly focused on lancet species, i.e., Dicrocoelium spp., and Eurytrema spp. [17,31-33]. In this study, the molecular genetic approach was used to characterize the partial region of rDNA, namely the ITS1 and the $5.8 \mathrm{~S}$ from 3 P. fastosum 
specimens. We, however, could not compare the ITS1 sequences with other members of the genus Platynosomum due to unavailability of data in GenBank or elsewhere. The results of our study will be useful for the genetic comparison with other dicrocoeliid species, especially in the genus Platynosomum. Further samples of Platynosomum spp. and other molecular markers are necessary to provide more information for future phylogenetic studies of this genus and genetic diversity in $P$. fastosum populations within and between geographical regions.

Considering the current taxonomic knowledge on $P$. fastosum, this species can be distinguished from P. illiciens by only 2 criteria of the class of hosts [11] and the testis shape. The sequencing of molecular markers of $P$. fastosum and $P$. illiciens could confirm the non-specificity of $P$. fastosum or the existence of cryptic species within the genus Platynosomum during their high intraspecific and morphological variability.

\section{ACKNOWLEDGMENTS}

We would like to appreciate the valuable contributions of the anonymous reviewers. This research was funded by Vietnam National Foundation for Science and Technology (NAFOSTED) under grant no. 106-NN.05-2014.21.

\section{CONFLICT OF INTEREST}

We have no conflict of interest related to this work.

\section{REFERENCES}

1. Basu AK, Charles RA. A review of the cat liver fluke Platynosomum fastosum Kossack, 1910 (Trematoda: Dicrocoeliidae). Vet Parasitol 2014; 200: 1-7.

2. Warren KS, Swan RA, Hobbs RP, Heriyanto, Kuhn EM, Heeney JL. Platynosomum fastosum in ex-captive orangutans from Indonesia. JWildl Dis 1998; 34: 644-646.

3. Kim JM, Che JH, Jeong DH, Kang BC. Platynosoum fastosum infestation in a domestic cat in Korea. Lab Anim Res 2010; 26: 307309.

4. Retnasabapathy A, Prathap K. The liver-fluke Platynosomum fastosum in domestic cats. Vet Rec 1971; 88: 62-65.

5. Mohd Zain SN, Sahimin N, Pal P, Lewis JW. Macroparasite communities in stray cat populations from urban cities in Peninsular Malaysia. Vet Parasitol 2013; 196: 469-477.

6. Nimsuphan B, Prihirunkij K, Pinyopanuwat N, Chimnoi W. Case report: mixed infection of Platynosomum fastosum and Clonorchis sinensis in cat. Kasetsart J Veter 2001; 11: 27-32.

7. Jittapalapong S, Inparnkaew T, Pinyopanuwat N, Kengradomkij
C, Sangvaranond A, Wongnakphet S. Gastrointestinal parasites of stray cats in Bangkok metropolitan areas, Thailand, Kasetsart. J Nat Sci 2007; 41: 69-73.

8. Le HK. New findings on the cat liver flukes in some southern provinces of Vietnam. Veter Sci Techn 2012; 19: 14-18 (in Vietnamese).

9. Ha DN. Trematodes from Birds and Mammals in the Central Highland of Vietnam. Ph.D. Dissertation, Institute of Parasitology, Soviet Union Academy of Sciences, Moscow, Russia. 1990, 158 pp. (in Russian).

10. Andrade RL, Dantas AF, Pimentel LA, Galiza GJ, Carvalho FK, Costa VM, Riet-Correa F. Platynosomum fastosum-induced cholangiosarcomas in cats. Vet Parasitol 2012; 190: 277-280.

11. Pinto HA, Mati VL, Melo AL. Can the same species of Platynosomum (Trematoda: Dicrocoeliidae) infect both mammalian and avian hosts? J Helminthol 2016; 90: 372-376.

12. Maldonado JF. The life history and biology of Platynosomum Kossak, 1910 (Trematoda, Dicrocoeliidae). PR J Public Health Trop Med 1945; 21: 17-39.

13. Nguyen TL, Ha DN. Trematoda: Paramphistomatida, Plagiorchiida. In Dang NT et al. eds, Fauna of Vietnam. Vol. 23. Hanoi, Vietnam. The Science and Technique Publishing House. 2007, pp 1-314.

14. Hillis DM, Dixon MT. Ribosomal DNA: molecular evolution and phylogenetic inference. Q Rev Biol 1991; 66: 411-453.

15. Orosová M, Ivica KH, Eva B, Marta S. Chromosomal characteristics of multiple rDNA clusters and intragenomic variability of ribosomal ITS2 in Caryophyllaeides fennica (Cestoda). Parasitol Int 2010; 59: 351-357.

16. Yamada S, Yoshida A, Yoshida K, Kuraishi T, Hattori S, Kai C, Nagai Y, Sakoda T, Tatara M, Abe S, Fukumoto S. Phylogenetic relationships of three species within the family Heligmonellidae (Nematoda; Heligmosomoidea) from Japanese rodents and a lagomorph based on the sequences of ribosomal DNA internal transcribed spacers, ITS-1 and ITS-2. Jpn J Vet Res 2012; 60: 1521.

17. Mohanta UK, Ichikawa-Seki M, Hayashi K, Itagaki T. Morphological and molecular characterization of Eurytrema cladorchis parasitizing cattle (Bos indicus) in Bangladesh. Parasitol Res 2015; 111: 2099-2105.

18. Skrjabin KI. Trematodes of Animals and Man. Vol. 1. Moscow, Russia. Academy of Sciences of the Union of Soviet Socialist Republics. 1947, pp 1-516.

19. Bray RA, Gibson DI, Jones A. Keys to the Trematoda, Volume 3. London, UK. CAB International and Natural History Museum. 2008, pp 1-825.

20. Nguyen TL. Animal and man parasitic trematodes: Fasciolida, Brachylaimida, Clinostomida, Cyclocoelida, Notocotylida, Opisthorchida, Renicolida, Schistosomatida, and Strigeidida. In Dang NT et al. eds, Fauna of Vietnam. Vol. 8. Hanoi, Vietnam. The Science and Technique Publishing House. 2002, pp 1-387.

21. Hoffman GL. Parasites of North American Freshwater Fishes. New York, USA. Cornell University Press. 1998, pp 1-539. 
22. Morgan JA, Blair D. Nuclear rDNA ITS sequence variation in the trematode genus Echinostoma: an aid to establishing relationships within the 37 collar-spine group. Parasitology 1995; 111: 609-615.

23. Tamura K, Stecher G, Peterson D, Filipski A, Kumar S. MEGA6: Molecular evolution genetics analysis version 6.0. Mol Biol Evol 2013; 30: 2725-2729.

24. Kimura M. A simple method for estimating evolutionary rate of base substitution through comparative studies of nucleotide sequences. J Mol Evol 1980; 16: 111-120.

25. Swofford DL. PAUP*: Phylogenetic Analysis Using Parsimony ( ${ }^{*}$ and other methods), version 4.0.b5. Sinauer, Sunderland, Massachusetts, USA. 2001.

26. Travassos L. The revised family Dicrocoeliidae Odhner, 1910. Monografias do Instituto Oswaldo Cruz 1944; 2: 1-357 (in Spanish).

27. Lenis C, Navarro F, Velez I. First case of platynosomiosis from Colombia: Platynosomum illiciens (Digenea: Dicrocoeliidae) in Felis catus, Turbo, Antioquia. Revista Colombiana de Ciencias Pecuarias 2009; 22: 659-663 (in Spanish).

28. Mas-Coma S, Bargues MD. Human liver flukes: a review. Res Rev
Parasit 1997; 57: 145-218.

29. Hung NM, Madsen H, Fried B. Global status of fish-borne zoonotic trematodiasis in humans. Acta Parasitol 2013; 58: 231-258.

30. Nguyen TL, Pham ND, Ngo HT. New data on trematodes parasitizing dogs of Vietnam. J Biol (Vietnam) 1998; 20: 1-5 (in Vietnamese).

31. Maurelli MP, Rinaldi L, Capuano F, Perugini AG, Veneziano V, Cringoli G. Characterization of the $28 \mathrm{~S}$ and the second internal transcribed spacer of ribosomal DNA of Dicrocoelium dendriticum and Dicrocoelium hospes. Parasitol Res 2007; 101: 1251-1255.

32. Otranto D, Rehbein S, Weigl S, Cantacessi C, Parisi A, Lia RP, Olson PD. Morphological and molecular differentiation between Dicrocoelium dendriticum (Rudolphi, 1819) and Dicrocoelium chinensis (Sudarikov and Ryjikov, 1951) Tang and Tang, 1978 (Platyhelminthes: Digenea). Acta Trop 2007; 104: 91-98.

33. Liu GH, Yan HB, Otranto D, Wang XY, Zhao GH, Jia WZ, Zhu XQ. Dicrocoelium chinensis and Dicrocoelium dendriticum (Trematoda: Digenea) are distinct lancet fluke species based on mitochondrial and nuclear ribosomal DNA sequences. Mol Phylogen Evol 2014; 79: 325-331. 